\title{
An Exploration of the Print Major Training Integrated With Innovation and Entrepreneurship Education in the New Era
}

\author{
Guoling Cui
}

\author{
School of Fine Arts \& Design, Baoshan University, Yunnan, China \\ *Corresponding author. Email: 372391419@163.com
}

\begin{abstract}
In the teaching of fine arts in colleges and universities, the print major is an important part, while print teaching is also one of the core majors in the field of fine arts. This major integrates printing, design, painting, engraving and other arts, with distinctive features and artistic characteristics. From the perspective of the teaching of print major, professional courses can play a certain role in promoting students' imagination, creativity, and aesthetic ability. In addition, the teaching of print major involves a kind of traditional art, and the current implementation is unsatisfactory. The future employment prospects of professional students are also relatively narrow, which will have a certain impact on the future career development, employment, etc. of professional students. It is necessary to think about relevant problems and study the teaching reform and innovation path of the professional courses.
\end{abstract}

Presently, the employment situation of college students is severe. With the gradual increase in the number of college graduates in recent years, the employment problem of college students has become increasingly prominent. In order to alleviate the employment pressure of college students, the education sector has proposed a strategic deployment of innovation and entrepreneurship education, which emphasizes the importance of deepening innovation and entrepreneurship education in the teaching in colleges and universities, and tries to strengthen the innovation and entrepreneurship abilities of professional students through the effective development of innovation and entrepreneurship education and improve their innovation and entrepreneurship abilities while promoting relevant professional students' learning of skills and professional knowledge. This paper takes the print major as an example to analyze the problems existing in its teaching in the innovation and entrepreneurship education of colleges and universities, analyzes the necessity of integrating print major into innovation and entrepreneurship education, and deeply explores the effective countermeasures of print majors' innovation and entrepreneurship education.

Keywords: Print major, integration, innovation and entrepreneurship education

\section{CURRENT STATUS OF THE TEACHING OF PRINT MAJOR IN COLLEGES AND UNIVERSITIES}

\subsection{Lack of Correct Course Teaching Cognition}

At this stage, in the teaching of print major courses in colleges and universities, the relevant teachers have an incomplete understanding of print teaching. Teachers fail to grasp the basic nature of print teaching accurately and lack the cognition of the importance of print. In the aspect of curriculum setting, and the selection of teaching methods, they are relatively traditional and lack innovation. In the teaching practice of professional courses of print, many teachers follow the traditional teaching mode and refer to the syllabus completely and carry out the teaching of the course according to routine. In the teaching process, teachers use too many teaching modes and methods of other majors for reference and imitated them too much, and they take oil painting and traditional Chinese painting and so on as references in the print teaching while ignoring the pertinence of print teaching. As a result, the print teaching and relevant equipment are mere formalities and lack the real teaching practical value.

\subsection{Insufficient Training of Students' Innovative Thinking}

Presently, in the teaching of print major in colleges and universities, students' overall course participation and their learning interest are not high, and they lack the enthusiasm for course exploration. From the perspective of the print course, the color scheme, the training of professional skills, etc. included in the course has relatively high requirements on students' specialty and technicality. However, teachers lack the training of students' innovative thinking in teaching, and students also lack freshness in learning during the course teaching. The teaching methods 
adopted by teachers in the teaching are single, relatively theoretical, and contain more technical content. Students have heavy learning tasks, and their interests are greatly reduced. In addition, course knowledge and content related to print mastered by students are relatively less. Therefore, it is difficult for college students to be trained in their innovative and expansive thinking. Students are used to the single course teaching mode of teachers and are relatively passive in the learning of the course, which is detrimental to the realization of the teaching goal of the course.

\subsection{High Employment Pressure of Graduates}

At present, the cultural integration has accelerated and the multicultural environment has been formed. In the face of the fierce employment situation and the cultural trend with modern accelerated development, the inheritance and development of traditional culture has suffered a blow to some extent. The current college students in the country have an unclear standpoint on cultural outlook, and they praise western values excessively, which has caused that they have some deviations and vacillations in their aesthetic experience and concepts. Some college students go after western artworks like a flock of ducks and elevate them as fine works, which is not good for their artistic creation and artistic career development. Besides, presently, college graduates are increasing. As a major that is relatively not so popular, there are relatively fewer professional students majored in print. There are also many students who are difficult to be concentrated and keep their patience in the learning of the print major and are susceptible to other external factors. All of these make it difficult for the print teaching quality to meet the requirements, which is detrimental to the inheritance and development of print art in the future and the employment and development of print professionals, and so on.

\section{IMPORTANCE OF INNOVATION AND ENTREPRENEURSHIP EDUCATION IN PRINT MAJOR}

\subsection{An Inevitable Need for the Training of Professionals}

To realize the inheritance and development of the art of print, it is necessary to innovate on the original basis and integrate it with the culture of the times. Therefore, the integration of innovation and entrepreneurship education in print teaching can strengthen the training of professional students' innovation ability to some extent and enable them to improve their cognition on print art and relevant arts continuously. Through the development of innovation and entrepreneurship education for professional students, on the basis of professional learning, professional students can be promoted to improve their cognition on innovation and entrepreneurship, intensify their innovation and entrepreneurship literacy and improve their skills on multiple aspects. This is a need of the training of professionals of print in the new era, which is of great significance for the improvement of the quality of the print professional training.

\subsection{The Need to Promote Smooth Employment and Entrepreneurship of Professional Students}

Presently, college graduates' employment problems are increasingly prominent. One of the main goals to develop innovation and entrepreneurship education is to alleviate the employment pressure of college students, promote the successful entrepreneurship of more college students, and improve their employment competitiveness. Developing innovation and entrepreneurship education for college students in print major can allow professional students to better recognize the current professional employment situation, clarify the basic skills and literacy they need to master in their professional employment, and grasp the requirements for professional posts, so as to make their own adjustments, upgrade their skills in related aspects and promote their successful employment and entrepreneurship. For print students, learning innovation and entrepreneurship courses can allow them to innovate artistic creation and future career development models in print major, provide guidance for their participation in related entrepreneurship projects, and promote the continuous optimization of their overall innovation and entrepreneurship abilities.

\section{COUNTERMEASURES OF INNOVATION AND ENTREPRENEURSHIP EDUCATION IN PRINT MAJOR}

\subsection{Strengthen the Innovation and Entrepreneurship Practice Teaching and Improve Professional Practice Skills}

In the light of the current teaching situation of print major in colleges and universities, in the specific course teaching practice, teachers should improve their understanding of the practical teaching of innovation and entrepreneurship education. Currently, many colleges and universities lay particular stress on theories in the innovation and entrepreneurship education, which is extremely harmful to the improvement of professional students' innovation and entrepreneurship skills. Therefore, related colleges and universities should strengthen students' innovation and entrepreneurship practice teaching, actively carry out related practical activities, implement various thematic education activities through the design of innovation and 
entrepreneurship practice activities to guide print students to go deep into the society, know more about national conditions, and enhance their abilities.

Colleges and universities should implement related student's party member education activities around the strategic planning of college students' innovation and entrepreneurship, and actively explore the close integration of innovation and entrepreneurship practice education with national conditions and social conditions education, and print major education. While developing the professional advantages of the college, combined with the actual development of the print industry in relevant areas, colleges and universities should actively participate in related cultural inheritance and project construction, thus making a little contribution to the inheritance of print art. For example, colleges and universities can organize students to form service groups to go deep into the birthplace of print to implement the print clothing color painting and design activities, so that students can apply solid print and painting skills in practice, and turn blank walls, buildings, curtains and other spaces into print culture carriers with brushes, thus adding a beautiful scenery to the area. In the creation, students can take the initiative to be close to the people's livelihood, have a heart-to-heart talk and get along with local residents. The organization of these activities can not only improve students' theoretical professional knowledge, but also brighten up the construction of print culture, so it has important educational value.

\subsection{Actively Innovate the Educational form and Conduct Diversified Print Competitions}

In the new era, colleges and universities should stimulate students' enthusiasm for the print innovation and entrepreneurship learning. In practice, colleges and universities should actively create an atmosphere for the print art learning, and can hold innovation and entrepreneurship competitions to create a vigorous campaign for innovation and entrepreneurship inside and outside of the campus. Related competition activities should be implemented closely around college students' innovation and entrepreneurship activities, to accelerate the accumulation of innovative and entrepreneurial talents, further create a strong atmosphere for innovation and entrepreneurship in related majors of colleges and universities, encourage students to actively participate in print innovation and entrepreneurship activities, and promote them to exercise their innovation and entrepreneurship skills in practice. The design of competition organization should be also around the organization of innovation and entrepreneurship and the topic selection of innovation and entrepreneurship, etc. For example, themed by print inheritance, it aims to incorporate innovation and entrepreneurship education with the whole process of talent cultivation, stimulate students' passion for innovation and entrepreneurship, and show the achievements of the school's innovation and entrepreneurship education and print major education.

To promote the reform of innovation and entrepreneurship education in the field of vocational education, a "vocational education track" can also be established in related competitions. Participants include higher vocational colleges and secondary vocational schools to encourage and attract more print students to join the innovation and entrepreneurship team and cultivate more high-quality cultural inheritors and professional and technical talents for the transformation and upgrading of China's economic structure. To increase the enthusiasm of teachers and students to participate in the innovation and entrepreneurship competition, and solidly advance the all work of the school competition, related colleges and universities should formulate the implementation plan for school competitions in accordance with the spirit of the relevant innovation and entrepreneurship competition documents, guide participating teachers and students from the summary of previous competitions, competition track rules, excavation of competition projects, business plan preparation, road show preparation, PPT design and production and precautions. Through learning guidance, participating teachers and students can be familiar with the rules of the competition, have a clearer thinking and direction for further cultivation and excavation of the project and grasp the main points and skills of the print innovation and entrepreneurship competition to ensure that they carefully plan and prepare for the competition, and strive to get satisfactory results in the competition. The organization of diversified competitions and activities allows the innovation and entrepreneurship education atmosphere in print major to be created to stimulate students' enthusiasm for innovation and entrepreneurship, so that students can exercise their skills, accumulate experience and improve the whole educational effectiveness in participating in innovation and entrepreneurship competitions and activities.

\section{CONCLUSION}

The Chinese culture is extensive and profound and has deep connotation. It is the rich cultural inheritance left by our ancestors. The print art is one of the traditional art forms. Integrating a variety of paintings and skills, it is a comprehensive cultural and artistic form and is widely used in social life, production and other fields at this stage. In the teaching of print major, deepening the innovation and entrepreneurship education is of great value to the cultivation of professional talents, the inheritance and development of culture and the advancing with the times of print art. Given the current innovation and entrepreneurship education work of print major in colleges and universities, there are still many problems, which are neither adverse to the development of professional teaching, nor the improvement of students' future employment and entrepreneurial competitiveness. Therefore, college and universities should actively innovate the education model, strengthen the practice of 
innovation and entrepreneurship teaching in print major, actively innovate the teaching form of innovation and entrepreneurship, stimulate students' learning interest, and stimulate students' enthusiasm for innovation and entrepreneurship through the organization of diversified innovation and entrepreneurship activities of print major and promote professional innovation and entrepreneurship education to achieve desired results.

\section{REFERENCES}

[1] Peng LV, Zhichen LIU, Dongfang HUANG, Dejuan HUANG. Research on the Improvement of College Students' Innovation and Entrepreneurship Ability Based on TRIZ Theory - Taking the course of "College Students' Innovation and Entrepreneurship Foundation" as an example [J]. Technology and Innovation, 2020 (24): $85-86+89$.

[2] Fengyun WANG, Shanguo WU. Exploration of Innovation and Entrepreneurship Education of Machinery Majors of Colleges and Universities Insisting on "Fostering Character and Civic Virtue and Three Elements of All-round Education" [J]. Education Science \& Culture Magazine (Mid-ten-day Issue), 2020 (12): 83-84.

[3] Zhiqiang WANG, Zehai LONG. Research on the Ability Structure of Innovation and Entrepreneurship Teachers in China's Colleges and Universities Based on the Organizational Support Mechanism - Based on Empirical Investigation of 1,231 Colleges and Universities [J]. Journal of East China Normal University ((Educational Sciences), 2020, 38 (12): 4252.

[4] Ling HU, Bo YANG. Research on the Influencing Factors of the Effect of Innovation and Entrepreneurship Education in Colleges and Universities - Based on the Data of 150 Universities and Colleges with Typical Experience in Innovation and Entrepreneurship in China from 2016 To 2018 [J]. Journal of East China Normal University ((Educational Sciences), 2020, 38 (12): 64-75.

[5] Haijie WANG. A Preliminary Study on the Innovative Teaching of Print Course in Comprehensive Art Major - Taking the Direction of Comprehensive Art Major of College of Art and Design, Zhejiang Sci-Tech University as an Example [J]. Education Modernization, 2019, 6 (92): 96-97.

[6] Minzi YANG. Research on the Role of Teaching Reform of the Print Course of Fine Arts (Normal) in Guizhou Normal Universities and Colleges in the
Discipline Construction [J]. Art Education Research, 2019 (10): 96-97.

[7] Haijie WANG. Teaching Research of Silk Screen Print Course in Commercial Illustration Major Taking the Commercial Illustration Major of College of Art and Design, Zhejiang Sci-Tech University as an Example [J]. Art Education, 2016 (12): 186-187.

[8] Qing LV. Research on the Connection between the Inheritance of Traditional Wood Engraving Picture and the Teaching of Print Major in Universities and Colleges - Taking Foshan Wood Engraving Picture as an Example [J]. Art Education, 2017 (13): 120-121. 